\title{
Homenaje al Profesor José del Carmen Acosta: Instituto de Protección Materna e Infantil Concepción Villaveces de Acosta
}

\begin{abstract}
La Revista de la Sociedad Colombiana de Obstetricia y Ginecología al transcribir en el presente número los discursos del Profesor Ferro y de los doctores Gustavo Riaño y Hernando Navas, pronunciados el día 19 de diciembre de 1953 en el ahora justamente llamado Instituto de Protección Materna e Infantil Concepción Villaveces de Acosta, quiere rendir, una vez más, un tributo de gratitud y admiración a los altísimos méritos del Profesor José del Carmen Acosta.
\end{abstract}

La Redacción.

\section{PALABRAS DEL PROFESOR LUIS M. FERRO:}

Señor Profesor José del Carmen Acosta V., señores miembros de la Junta General de Beneficencia, señoras, señores, compañeros:

La honorable Junta General de Beneficencia en su sesión del día 3 de noviembre y a petición de los Jefes de Clínica e Internos del Instituto aprobó la siguiente resolución:

\section{LA JUINTA CONSIDERANDO:}

Que el señor Profesor José del Carmen Acosta Villaveces actualmente Director Científico del Hospital de San Juan de Dios, fue por largos años y también con brillo y eficacia insuperables, Médico Director del Instituto de Protección Materno-Infantil;

Que tanto en el desempeño de ese cargo como en su cátedra de Clínica Obstétrica ha puesto su desvelado interés al servicio del Instituto, y ha laborado en favor del progreso de éste con la más abundante generosidad; y

Que tanto los Jefes de Clínica como los Internos del Instituto se han dirigido a esta Junta, con unanimidad, para pedir que se rinda un homenaje a esa labor benemérita, y sugieren que le sea dado a aquella entidad el nombre de la señora madre del Profesor,

R E S U E V E :

Artículo 1?-En lo sucesivo se denominará "Instituto Materno-Infantil Concepción Villaveces de Acosta" el que hoy funciona dependiente de la Beneficencia de Cundinamarca. 
Artículo $2^{\circ}-$ En ceremonia especial, que se efectuará oportunamente se colocará una placa que recuerde lo aquí dispuesto, en uno de los muros del Instituto.

Comuníquese y cúmplase.

Roberto García Paredes, Priesidente.

Roberto Liévano, Secretario.

Profesor:

Los más nobles sentimientos de nuestros corazones se unen hoy para tributar emocionado homenaje a la memoria de vuestra madre, prototipo de la mujer colombiana, de las madres que hacen patria, de la que llenó de ternura $y$ caricias vuestra niñez, alero cariñoso en vuestra adolescencia y anantísima fuente donde vuestra juventud bebió a cántaros todas las nobles virtudes de que hacéis gala en vuestra fecunda vida profesional y social.

Concepción Villaveces, bellisima flor del Tolima grande, venida al mundo de un hogar modelo en Purificación unió muy joven su suerte a la de un muy distinguido ingeniero el doctor José del Carmen Acosta vuestro padre.

Bendijo el cielo este hogar feliz con seis vástagos. Tres mujeres y tres varones.

Aguda dolencia segó muy pronto la existencia del prestigioso ingeniero y entonces tú sola, en la vida, fragilísima y delicada criatura, con sin igual valor y entereza tomasteis el timón del hogar y como la mujer fuerte del Evangelio luchasteis contra la adversidad y la pobreza, $y$ de esas frágiles cunitas, arrullados con todo vuestro amor y ternura y en un ambiente eternamente perfumado con vuestras virtudes lograsteis levantar un hogar que me permito hoy mostrar como ejemplo y orgullo de la sociedad colombiana: fesión.

Hernando, abogado que ha ocupado las más altas posiciones en su pro-

Jorge, el más respetado y brillante profesor que ostenta la Facultad de Matemáticas e Ingeniería.

José del Carmen, Médico y Cirujano que ocupa entre nosotros la más merecida y destacada posición.

Conchita y María Teresa han dedicado su vida y sus virtudes a mantener vivo el hogar feliz.

Mercedes que unió su vida a la de nuestro lamentado amigo el Profesor José Sarmiento a quien rindo el más cariñoso recuerdo.

Nuestros cuadros profesionales ostentan ya los nombres de vástagos de nueva generación en esta privilegiada familia y así contamos en medicina con los nombres de José Rafael Sarmiento Acosta y Eduardo Acosta Lleras, Antonio José y Alfonso Acosta Lleras en la ingeniería, dignos herederos de tan ilustre prosapia.

Y qué decir por parte de la familia Villaveces:

El doctor Julián Villaveces honra de la profesión de ingeniero.

Tulio Forero Villaveces, médico y Profesor a quien nuestra Fạcultad rodea 
de admiración y cariño y la maravillosa inteligencia y profundo saber que distinguen a Lope Prada Villaveces.

Este establecimiento es hoy en día la institución de más honda proyección en los servicios de Asistencia Social. Aquí se educa y cuida a la madre menesterosa en su período prenatal, se la atiende y consuela en el difícil trance de la maternidad y se le cuida a su recién nacido hasta cumplir el primer año de vida. Aqui se hace la verdadera caridad, y debo aprovechar esta ocasión para, en nombre de tantas madres, en nombre de nuestra ciudad dar a la Junta de Beneficencia y al Sindico Gerente gracias por su maravillosa labor en bien de la clase más necesitada de ayuda y menos amparada en nuestra sociedad.

Cuántos esfuerzos y cuán desvelado interés he visto en todos ellos para arbitrar recursos con los cuales hemos podido dotar en buena forma esta Maternidad y daros también las gracias por este homenaje rendido al que ideó y con vuestra colaboración llevó a cabo esta institución, al que ha sido su Director y es su alma y guía permanente, al que abandonando casi por completo la más distinguida, numerosa y merecida clientela que ha conocido dedica actualmente todas sus capacidades, toda su consagración y entusiasmo a la organización de este nuevo y majestuoso Hospital de San Juan de Dios, orgullo de Sur América.

Profesor: Todas las distinciones y honores que nuestra profesión tiene, las han alcanzado vuestras virtudes y merecimientos: y cuantas habéis declinado.

Os he visto recibirlas sin que ello alterara en lo más mínimo vuestra sensibilidad, frenada por una férrea voluntad y una orgullosa humildad, pero cuando en reciente ceremonia Lisandro Leyva Pereira con voz alterada por el cariño y la emoción leía la carta en la que el personal científico pedía por su conducto a la Junta de Beneficencia la consagración del Instituto a la memoria de vuestra adorada madre, vuestra alma grande rompió de súbito estas vallas y en forma de gruesas lágrimas invadió de emoción gratísima todo el ambiente de tan recordada reunión.

Al expresar tan pobremente los sentimientos de profunda admiración y gratitud que a todos nos animan quiero, implorando la sagrada memoria de la que os dio el ser, pedirle que su ejemplo y su nombre presidan siempre todas nuestras actividades y que cuando a altas horas de la noche vengáis a prestar vuestra valiosa ayuda a la madre desvalida, sea a la vuestra que honréis y en ella a la madre colombiana, a las nuestras y que al seguir vuestro ejemplo logremos el título que vos, con mayor orgullo ostentáis,

El de ser digno hijo de vuestra madre.

He dicho.

\section{PALABRAS DEL DOCTOR GUSTAVO RIAÑO-ALVAREZ:}

Señor Profesor José del Carmen Acosta, señores miembros de la honorable Junta General de Beneficencia, señoras, señores:

Los compañeros de trabajo en este Instituto, reconociendo la labor benemérita del Profesor José del Carmen Acosta Villaveces, resolvieron solicitar de 
la honorable Junta General de Beneficencia, se diera el nombre de "Protección Materno-Infantil Concepción Villaveces de Acosta" a esta dependencia y así nació la idea que galantemente fue aceptada y cristalizada por Resolución numero 13 de fecha 3 de noviembre de 1953.

Los mismos colegas me confiaron la misión de ofrecer el brindis en este acto y para dar cumplimiento a ello, brevemente anotaré algunos de los muchos títulos que lo hacen digno de la admiración y el aprecio que unánimemente se le profesa.

Graduado el 14 de julio de 1917 hizo la carrera del Profesorado con los siguientes cargos en la Facultad de Medicina de la Universidad Nacional:

1913, Director de Anatomía 11.

1914, Practicante Externo.

1915, Practicante Externo Clínica Médica.

1916, Jefe de Clínica Médica.

1917. Jefe de Trabajos de Laboratorio (Interinidad) y Jefe de Clinica Médica.

1918, Jefe de Clínica Quirúrgica y Profesor interno del curso de Clínica Quirúrgica.

1927, Profesor Titular de Biología.

1928, Profesor Encargado de Cátedra de Obstetricia.

1931, Profesor de Obstetricia.

1935, Profesor Encargado de Cátedra de Clínica Obstétrica.

1938, Profesor Titular de Clínica Obstétrica.

1939, Profesor del Departamento Obstétrico.

1941, Profesor Jefe del Departamento Obstétrico.

1944, Profesor Jefe de Clînica Obstétrica.

También ha sido: Miembro del Consejo Directivo de la Facultad de Medicina y Rector de la Facultad; Miembro del Consejo Directivo de la Universidad Nacional; Profesor y Decano de la Facultad de Medicina de la Universidad Javeriana; Presidente en varios periodos de la Sociedad Colombiana de Obstetricia y Ginecología; Presidente de la Federación Médica Colombiana; actualmente Presidente de la Academia de Medicina y Presidente de la Federación Médica Panamericana. Ha asistido a varios congresos científicos dentro y fuera del pais.

Gran progreso bajo su dirección han alcanzado el Instituto de Protección Materno-Infantil y el Hospital de San Juan de Dios. Parte muy importante ha tomado en la redacción del Código de Moral Médica por salir y en la elaboración de la ley sobre reglamentación del ejercicio de la medicina que se encuentra en estudio.

Con una trayectoria científica, tan lujosa como merecida por su aptitud y constancia para el trabajo, por su moderación y paciencia adornadas en modestia, se ha formado maestro inmejorable. Ha esculpido brillantemente su estirpe de caballero respetando con honor y gallardia a sus colegas y a quienes han tenido que ver con él, y asimismo se ha hecho respetable. 
Elegantemente ha estimulado la crítica constructiva y ha sabido rechazar el ataque sin fundamento verdadero. Nunca las pasiones de cualquiera indole no científica han influído en sus actuaciones. Ha aceptado el puesto de abanderado en defensa de la profesión y sus representantes, pero jamás en beneficio propio. En hospitales, en su consultorio, en clínicas, en facultades de enseñanza, $y$ en fin, en las numerosas entidades a las cuales ha repartido el tiempo de su vida en beneficio de todas las clases sociales, ha servido de ejemplo para quien quiera cumplir con las obligaciones y deberes que le impone el eiercicio de la profesión, porque ante todo y por sobre todo ha obrado como médico.

Continúa aumentando su obra científica que es más grande por no ser teórica sino por estar constituída en forma práctica y viviente en profesionales que ha formado para tener de esta manera mayor oportunidad de perdurar sirviendo activamente a la humanidad.

Brindemos porque la consagración de afecto filial que simboliza este homenaje sea el refleio de la gratitud de quienes han recibido el beneficio de sus atributos como médico, como maestro, como amigo o como gran patriota.

\title{
PALABRAS DEL DOCTOR HERNANDO NAVAS-ANGEL
}

\author{
en nombre de la
}

\section{Sociedad Colombiana de Obstetricia y Ginecología}

Señor Profesor José del Carmen Acosta, señores miembros de la Junta General de Beneficencia de Cundinamarca, señor Síndico, señor Decano de la Facultad de Medicina, señores Profesores, señores médicos del personal científico del "Instituto Materno-Infantil Concepción Villaveces de Acosta", señoras, señores:

La Sociedad Colombiana de Obstetricia y Ginecología me ha honrado al designarme para representarla en este justísimo homenaje al Profesor Acosta y para expresar su solidaridad con quienes oportunamente hemos querido mostrarle nuestra gratitud y admiración.

Así, Maestro, en mi doble condición de miembro del personal científico del Instituto de Maternidad que desde hoy se honra con el nombre de vuestra madre y de delegado de la Sociedad Colombiana de Obstetricia y Ginecología, quiero unir mi voz de discípulo agradecido a las muy autorizadas que os han expuesto el significado de nuestro homenaje.

Es a vos, Profesor Acosta, a quien nosotros imitamos descubriéndonos reverentes ante el nombre y la memoria de vuestra santa madre. No hacemos más que secundar el tributo de amor que a ella habéis rendido y rendis diariamente en las personas de miles de madres a quienes con devoción, sabiduría y caridad habéis dado y dais alivio y dicha, en el bien protegido y logrado fruto de sus entrañas. $Y$ vuestro filial tributo se prolonga a través de las sucesivas generaciones de vuestros discípulos, que hemos tomado como normas profesionales vuestro eiemplo y vuestra enseñanza. 
Habéis desalojado del hermoso y pagano juramento hipocrático a los dioses $y$ diosas del Olimpo y en su lugar habéis puesto a Cristo y a la Patria, que ahora os premian, porque no podrían demandároslo, el cumplimiento cabal de las obligaciones de cristiano y de médico, a que habéis dedicado vuestra meritoria vida.

Gracias, Maestro, en mi nombre y en el de todos vuestros discípulos, por vuestras sabias enseñanzas, gracias en nombre de todos los enfermos que han sido objeto de vuestra caridad y vuestra ciencia, gracias en nombre del cuerpo médico colombiano cuyos destinos gremiales orientáis con incomparable acierto, gracias, en fin, en nombre de la Sociedad Colombiana de Obstetricia y Ginecología, de la que sois espíritu de vida. 